\section{Abstract}

Globally, disasters disrupt human lives and women tend to be more vulnerable during such events. This narrative review explores women's experiences during disasters and identifies common factors increasing their vulnerability. After critical reading, 39 articles were included in this review. This paper underlines the themes in that literature to show that women across the world experience domestic violence, sexual assault, psychological and health problems as well as social and financial deprivation in disasters. The paper discusses the vulnerability of women particularly in Australia and New Zealand, through the lens of the global experience of women in disaster. This review highlights that, while there is consensus on the challenges faced by women in Australia, more research regarding interventions is required to reduce the negative effects of disasters on women. This review aims to inform emergency management practice in Australia and to direct further research to improve the outcomes for women and their safety.

\title{
Understanding the experiences of women in disasters: lessons for emergency management planning
}

Peer Reviewed

Dr Tazrina Jahan

Chowdhury ${ }^{1}$

Professor Paul Arbon ${ }^{1}$

Dr Mayumi Kako ${ }^{1}$

Dr Robert Muller ${ }^{1}$

Dr Malinda

Steenkamp ${ }^{1}$

Professor Kristine

Gebbie $^{1}$

1. Flinders University,

Adelaide, South Australia.

\section{SUBMITTED \\ 16 September 2021}

\section{ACCEPTED}

16 December 2021

DOI

www.doi.org/10.47389/37.1.73

\section{(c) (1) (3)}

(1) 2022 by

License Australian Institute

for Disaster Resilience,

Melbourne, Australia. This

is an open access article

distributed under the terms

and conditions of the Creative Commons Attribution

(CC BY) license (https://

creativecommons.org

licenses/by/4.0/).

\section{Introduction}

Gender equity and reducing inequality are 2 prominent priority Sustainable Development Goals to be achieved by 2030 (UNDP 2015). The Sendai Framework for Disaster Risk Reduction 2015-2030 acknowledges the importance of gender equity and the central role of women in preventive disaster management and building resilience (UNDRR 2017). These global frameworks underline international concern that women remain at a disadvantage in preparing for, surviving through and recovering from disasters. They are usually the most vulnerable group in a disaster context (WHO 2010), although the extent of women's vulnerability and exposure to hazards may vary and depend on a range of social, economic and cultural factors, as well as their vulnerability, and the level of exposure experienced (Ginige, Amaratunga \& Haigh 2014; Rezaeian 2013).

This paper summarises features of women's vulnerability and experiences during and after disasters to improve the understanding of their vulnerability and depict the parallels between global and Australian/New Zealand vulnerability in disasters. An understanding of the vulnerability of women in the local region places Australian emergency management practice in context and suggests further research to improve women's experiences and wellbeing in disasters.

\section{Method}

A narrative review is a non-systematic review that summarises the published literature on a specific topic or concept to reveal a new perspective based on existing knowledge, and to direct further research on the topic, thereby avoiding duplication of research (Ferrari 2015). The literature related to women's experiences during and after disruptive events was searched using combinations of keywords of 'women', 'disasters'/'disaster', 'emergencies'/ 'emergency', 'gender', 'post-disaster', 'bushfire'. To identify a specific sub-set of the literature, the name of the countries 'Australia' and 'New Zealand' were used. Articles written 
in English and published in or after 2007 were selected to provide relevance and validity of content. Additional articles were included after checking the reference lists of the identified papers. Searching continued until saturation was reached. After reviewing the titles of the identified papers, 74 papers including refereed papers and grey literature were obtained using electronic databases Scopus, ProQuest, Science Direct, Elsevier and Google Scholar. Articles were eliminated if there were inadequate referencing or lack of understanding due to language. In total, 39 articles were included after critical reading.

\section{Results and discussion}

The papers highlight how women's disaster-associated experiences across the globe align with women's challenges in Australia and New Zealand during and after disasters, irrespective of socio-economic class and cultural background. Despite evidence of women contributing to disaster preparation and response by building resilience in communities, the reported negative experiences by women generally outnumber the positive. The most notable among adverse outcomes were domestic violence, sexual assault and gender discrimination.

\section{Domestic violence and intimate partner violence}

Domestic violence and intimate partner violence are experienced by $30 \%$ of women worldwide under a wide range of circumstances (WHO 2017). However, during and after disasters, women experience higher rates of domestic violence and intimate partner violence. These occurrences are often overshadowed, and at times explained away, by other pressing matters associated with recovery and reconstruction after disasters.

Harville and co-authors (2011) investigated the extent of intimate partner violence after Hurricane Katrina in the Gulf Coast region of the United States using the Conflict Tactics Scale (a recognised instrument in domestic violence research used to quantify different forms of violence). The Conflict Tactics Scale was completed by 123 women affected by the hurricane and showed the level of violence they experienced. The findings were that nearly $5 \%$ of the respondents had been raped, sexually abused and/or battered on at least one occasion after the event. Excluding this 5\%, the remaining respondents reported that they had been emotionally compromised and/or verbally abused, with $87 \%$ humiliated or insulted an $19 \%$ slapped, shoved and/or pushed repeatedly by their partners. Campbell and co-authors (2016) interviewed 208 women affected by the earthquake in Haiti, with $62 \%$ identifying as victims of physical assault and $80 \%$ of this sub-group being attacked by their partners and in some cases, their ex-partners. This highlighted the inability of women to reach out for help within their communities. This triggered mental health issues including depression, anxiety and posttraumatic stress disorder among the respondents.

Fisher (2010) and Pincha (2008a) provide evidence of increased levels of domestic violence and intimate partner violence in the temporary shelters in India and Sri Lanka after the 2004 tsunami. Fisher (2010) conducted 60 semi-structured interviews in tsunami-affected areas and documented incidents of beatings and murders of women by their husbands, often as a result of excessive alcohol or drug use and intoxication. The author also recorded brutal killings, including a husband burning his wife to death. Both Hines (2007) and Pincha (2008) worked on the tsunami disaster and its impacts on people in Tamil Nadu, India. They conducted qualitative research and a survey that confirmed the increased domestic violence towards women in the temporary shelters of these regions.

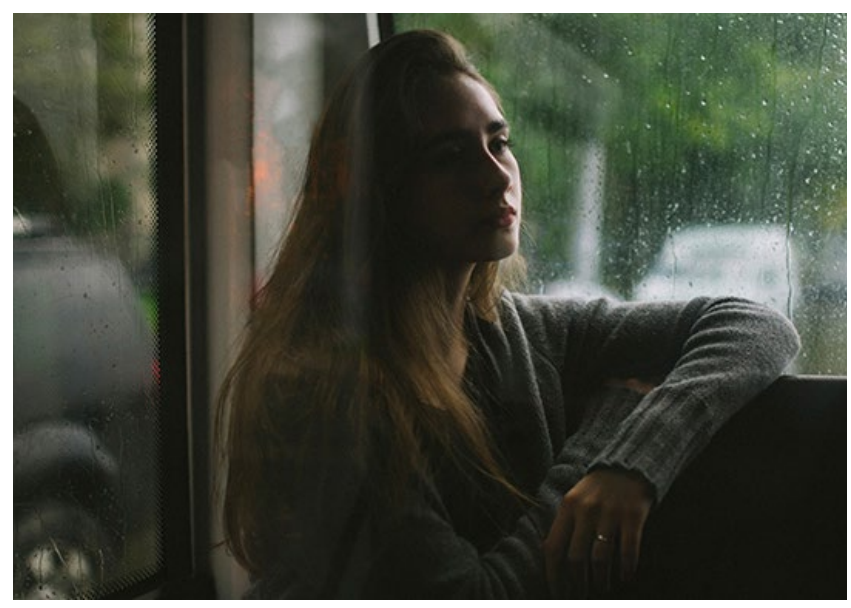

Research into intimate partner violence after Hurricane Katrina revealed an increase in incidents and that victims cannot easily reach out for help

Image: American Psychological Association

\section{Gender-biased socio-cultural practices}

Day-to-day, gender-biased, socio-cultural practices, household and community responsibilities and expectations of women may cause undesirable experiences for women during and after disaster. This has an impact on their rights, health and safety. Fagen and colleagues (2011) identified that, during the evacuation phase of Hurricane Katrina, women from New Orleans were not well-prepared for evacuation. Many did not get assistance from their partners and children were solely dependent on their mothers. This delayed the evacuation process for women. In some cases, the lack of willingness by male counterparts, and the taken-for-granted maternal culture, meant women took on full responsibility for their families and households in the posthurricane stage. Men, living in the shelters during the recovery stage or in their houses after the recovery-rehabilitation stage, were reported by Thornton and Voight (2007) to have spent more money on personal entertainment than on household needs. As a result, many women had to take on responsibility for providing food for their families (Thornton \& Voigt 2007).

Nelson and co-authors (2002) argued that women from many cultures are expected to take sole responsibility for a range of activities including organising food and caring for children and sick family members. For example, during the recurrent floods in Manila in the Philippines, 68 female survey participants reported the expectation to take care of family during the flood emergencies, with $78 \%$ being responsible for providing food for family members and $56 \%$ looking after sick family members (Reyes \& Lu 2016). In listing women's priorities, Reyes and Lu 
(2016) found that the women themselves prioritised caring for their family members and protecting their households over personal care and safety. The tendency of prioritising others led many women to die in Sri Lanka during the 2004 tsunami because women kept gathering household belongings and checking on family members, which delayed their evacuation (Jayarathne 2014). While staying in the temporary shelters after the 2004 tsunami in Sri Lanka, many men, driven by a false sense of ego and superiority as reported by Jayarathne (2014), refused to attend the relief centres. They forced female family members to travel from the shelters to relief distribution centres multiple times a day to line-up for several hours to collect relief supplies on the men's behalf. This put additional physical and psychological stress on the women in addition to their existing household responsibilities (Jayarathne 2014).

The male-controlled relief distribution management system in India, Sri Lanka and the Philippines did not accommodate for the purchase of women's essentials such as sanitary napkins, hygiene products, nutritious food for pregnant women and birth-control pills after the 2004 tsunami and Typhoon Haiyan (Valerio 2014, Pincha 2008a, Jayarathne 2014).

Gender-blind disaster management guidelines were also evident in Iran after the East Azerbaijan twin earthquakes in 2012 and the Bushehr earthquake in 2013. Despite women comprising half the total population (Statistical Centre of Iran 2013), they were not included in any disaster management and rehabilitation activities as women in the affected areas were considered a weaker group in the community and, therefore, incapable of contributing to issues as important as managing disasters (Sohrabizadeh 2016).

\section{Other global issues}

This review showed that, globally post-disaster, women face more unemployment and financial discrimination than men. Women staying in the evacuation centres in Tohoku, Japan after the tsunami of 2011, worked voluntarily in the shelter kitchens whereas male evacuees were offered paid jobs such as collecting debris (Saito 2012). After the 2004 tsunami in the Maldives, many employers recruited internally displaced men to replace their female workers, resulting in a $5 \%$ increase in the rate of women's unemployment (Fulu 2007). Financial discrimination and dependence on men put women into delayed rehabilitation and resulted in increased theft, begging, and prostitution following disasters (Juran 2012, Gokhale 2008, Takasaki 2012, IFRC 2016).

Disaster-affected women frequently experience health challenges as a result of their physiological needs not being addressed in emergencies and during relief budget allocations. Thapa and Acharya (2017) found that after the 2015 Nepal earthquake, the care of pregnant women was not prioritised in the disaster areas. Local authorities considered that pregnancy was a natural physiological condition and needed no additional consideration in emergencies. This triggered anxiety and depression among many pregnant women. In 2013, when super Typhoon Haiyan struck the Philippines, over 270,338 pregnant women suffered either a lack of skilled birth attendants during childbirth or inadequate treatment facilities for obstetric complications such as pre-eclampsia, eclampsia and sepsis (Valerio 2014).

Women from minority groups generally appear to experience more adverse outcomes during and after disasters. Pongponrat and Ishii (2018) focused on the vulnerabilities of a minority group of Thai women living in Ishinomaki, Japan. During the 2011 tsunami, their experience of evacuation and survival was more difficult because they had not participated in pre-disaster tsunami evacuation drills and there was insufficient support for them compared to Japanese citizens.

During the post-tsunami recovery phase in Tamil Nadu, India, women from the lower-caste Hindu Dalit community, identified as the most deprived group in the country, remained largely excluded from recovery policies and did not receive any compensation and/or financial aid (Pincha 2008b).

Enarson (2012) showed that racial issues in the Unites States put women of colour into vulnerable situations during disasters, with African-American women in many states receiving less assistance than did white women.

The literature selected suggests that regardless of women's ethnicity and socio-cultural background, their experiences of disaster events show a distinct and recurring pattern of violence, inadequate health support and added pressure to fulfil household responsibilities that affects their wellbeing around the world.

\section{Women's experiences in Australia and New Zealand}

In terms of post-disaster domestic violence and intimate partner violence, the experience of women in Australia and New Zealand was similar to the global experience of women.

Parkinson (2017) explored the incidence of post-disaster intimate partner violence among women who lived through the Black Saturday bushfires in Victoria, Australia in 2009. Thirty women were interviewed who had experienced intimate partner violence following the fires. A total of 16 reported violence after the bushfire (14 experiencing it themselves and 2 reporting violence experienced by family members). Of these respondents, 9 were victimised for the first time in the relationship and the other 7 had previous experience of violence in their relationship, with the fires escalating the violence.

After the 2010 series of earthquakes in the Canterbury region of New Zealand, domestic violence including child abuse and intimate partner violence rates increased in the affected areas (Campbell \& Jones 2016). Callouts made during the weekend following the earthquakes to the New Zealand police for domestic violence increased by $50 \%$ over the 'normal' rate (Houghton et al. 2010). Even though the number of these incidents doubled, it was projected that almost $76 \%$ of total domestic violence incidents during the recovery stage were not reported to police (Campbell \& Jones 2016). In addition, the incidence of domestic violence increased by almost $50 \%$ over the previous year (Ingber 2011). The literature on increased domestic violence and intimate partner violence following New 
Zealand earthquakes suggested that the filed complaints were regarded as sudden outbursts from male partners and therefore ignored. This indicates the barriers that women face in accessing assistance from support organisations (Campbell \& Jones 2016).

Most of the literature on women's experiences, did not specify the underlying reasons behind domestic violence and intimate partner violence. The trends reported by the respondents suggested that violence was persistent from their partners and that frustrations from uncertainty and insecurity after the disaster was a catalyst for the violence. For example, almost $47 \%$ of the female participants in the Australian study who were assaulted for the first time in their relationship, acknowledged receiving disrespectful gestures from their partners multiple times beforehand and foreseeing the tendency for violence in their partners (Parkinson 2017). The culture of denial and deeply embedded male-dominated social structures gave men the opportunity to get away with such offences because, in many cases, these incidents were overlooked by law enforcement personnel, health workers, neighbours and even the victims themselves who rationalise spousal abuse as an understandable response to post-disaster trauma and frustration for men (Campbell et al. 2016, Fagen et al. 2011, Harville et al. 2011, Parkinson 2017).

Similar to women's experiences in disasters across the globe, women in Australia and New Zealand experience discrimination and inequity in their households as a consequence of the patriarchal social structure (Parkinson \& Zara 2011, Reynolds \& Tyler 2018). Eriksen (2014) conducted a survey interview with 44 participants ( 26 women and 18 men) to identify the issues affecting women's involvement in bushfire preparedness activities. Of the respondents, $78 \%$ strongly agreed or agreed that during a bushfire emergency, women are more likely to rely on male family members and peers for warning information, evacuation instructions and rescue activities. This can, at times, prevent them from taking action during emergencies.

Reynolds \& Tyler (2018) argued that the preparedness and rescue practices of firefighters and volunteers have been highly masculinised and that evacuation was portrayed as 'for the weak' and considered as 'feminine' behaviour, which is one of the reasons for the disproportionately high percentage of male firefighters, officials and civil volunteers during bushfires. Although the Australasian Fire and Emergency Services Authorities Council (AFAC) has adopted a strategy to increase women's representation in the fire management sector, the percentage of women's overall representation is only $24 \%$ (AFAC 2019). This is still inadequate considering women comprise more than half the Australia's total population (Australian Bureau of Statistics 2021).

Because of gender bias, women's roles are often devalued within their households. Parkinson (2017) described women's despair at not being taken seriously by their male partners during the Black Saturday bushfires. A similar argument was made by Tyler and Fairbrother (2018) finding that women's knowledge of bushfire preparedness and response was often devalued and ignored in the male-dominated rural areas of Australia and that females in heterosexual relationships experience frustration and difficulty in convincing their partners to evacuate early.

Similar to the issues faced by various ethnic groups in the country, women of Aboriginal or Torres Strait Islander background have also faced challenges in getting involved in community resilience programs because the management approach of the Australian Government does not often recognise nor include Indigenous gender issues (Russel-Smith 2017).

\section{Lessons for Australia}

The selection of existing literature on women and disasters reviewed for this paper, both in a global context and in the Pacific region, highlights women's vulnerability and exposure and the disproportionate effects of disasters on them. Even though a dialogue on the gendered nature of disaster events has been opened, and research has been undertaken on these issues over time (of which this paper reviews a selection), women's voices have remained relatively unheard and are not effectively incorporated into national policies. This continues to have negative consequences for women's wellbeing during disasters around the world.

Strategies should be revisited to minimise domestic violence, recognise it as a consequential outcome during the recovery phase and put in place suitable services. Women should be consulted frequently and included by organisations that have crucial roles during planning and preparedness activities. The particular needs of women, including financial support, employment and health needs should be identified and assimilated into existing response and recovery plans. Ethnic diversity and lifestyles should be acknowledged and incorporated in planning and policies to maximum the inclusion of women to develop practical and sustainable resilience plans.

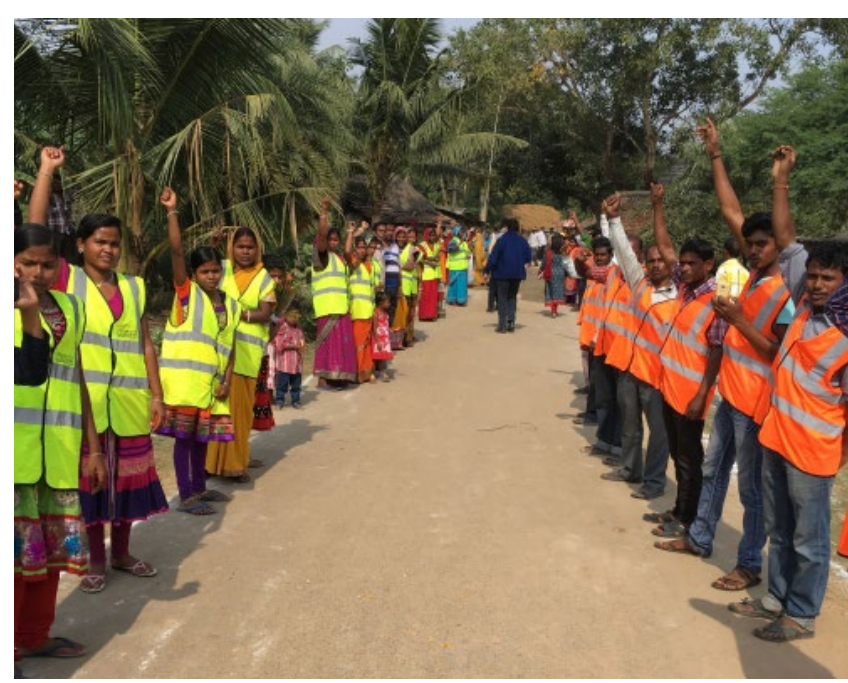

In India, multi-purpose shelter task forces carry out search, rescue and first aid and have $50 \%$ participation of women, which strengthens their capacities and the capacity of the community.

Image: World Bank 


\section{Conclusion}

The recurring issues faced by women in disasters highlight the significant need for their input into emergency management policies because people who have lived experiences can inform the decisions about important considerations in an inclusive manner. Future research should develop better understandings of women's experiences, considering age, ethnicity, education and qualifications, marital status, levels of financial independence and other variables to distinguish patterns of women's changing perceptions of their life situations in disasters. This can develop an improved understanding of women's roles and potential in emergency and disaster preparedness and response activities, and in building the resilience of families and communities.

\section{References}

AFAC 2019, Male champions of change: Fire and emergency impact report 2018-19. At: https://championsofchangecoalition. org/wp-content/uploads/2020/03/Fire-Emergency-ImpactReport-2019.pdf.

Australian Bureau of Statistics 2021, Regional population by age and sex. At: www.abs.gov.au/statistics/people/population/ regional-population-age-and-sex/2020\#data-download.

Campbell DW, Campbell JC, Yarandi HN, O'Connor AL, Dollar E, Killion C, Sloand E, Callwood GB, Cesar NM, Hassan M \& Gary F 2016, Violence and abuse of internally displaced women survivors of the 2010 Haiti earthquake, International Journal of Public Health, vol. 61, no. 8, pp.981-992. doi:10.1007/s00038-016-0895-8

Campbell LM \& Jones SJ 2016, An innovative response to family violence after the Canterbury earthquake events: Canterbury family violence collaboration's achievements, successes, and challenges, Australasian Journal of Disaster and Trauma Studies, vol. 20, no. 2, pp.89-100.

Enarson E 2012, Women confronting natural disaster: From vulnerability to resilience, CO: Lynne Rienner Publishers, Boulder, USA.

Eriksen C 2014, Gendered risk engagement: Challenging the embedded vulnerability, social norms and power relations in conventional Australian bushfire education, Geographical Research, vol. 52, no. 1, pp.23-33. doi:10.1111/1745-5871.12046

Fagen JL, Sorensen W \& Anderson PB 2011, Why not the University of New Orleans? Social disorganization and sexual violence among internally displaced women of Hurricane Katrina, Journal of Community Health, vol. 36, no. 5, pp.721-727. doi:10.1007/s10900-011-9365-7

Ferrari R 2015, Writing narrative style literature reviews, Medical Writing, vol. 24, no. 4, pp. 230-235. At: www.tandfonline.com/ doi/full/10.1179/2047480615Z.000000000329.

Fisher S 2010, Violence against women and natural disasters: Findings from post-tsunami Sri Lanka, Violence Against Women, vol. 16, no. 8, pp.902-918. doi:10.1177/1077801210377649
Fulu E 2007, Gender, vulnerability, and the experts: Responding to the Maldives tsunami, Development and Change, vol. 38, no. 5, pp.843-864. doi:10.1111/j.1467-7660.2007.00436.x

Ginige K, Amaratunga D \& Haigh R 2014, Tackling women's vulnerabilities through integrating a gender perspective into disaster risk reduction in the built environment, Procedia Economics and Finance, vol. 18, pp.327-335. At: http://linkinghub. elsevier.com/retrieve/pii/S2212567114009472.

Gokhale V 2008, Role of women in disaster management: An analytical study with reference to Indian society, in The 14th World Conference on Earthquake Engineering October, pp.12-17.

Harville EW, Taylor CA, Tesfai H, Xiong X \& Buekens P 2011, Experience of hurricane Katrina and reported intimate partner violence, Journal of Interpersonal Violence, vol. 26, no. 4, pp.833-845. doi:10.1177/0886260510365861

Hines RI 2007, Natural Disasters and Gender Inequalities: The 2004 Tsunami and The Case of India, Race, Gender and Class, vol. 14, no. 1/2, pp.60-68.

Houghton R, Wilson T, Smith W \& Johnston D 2010, If there was a dire emergency, we never would have been able to get in there: Domestic violence reporting and disasters', International Journal of Mass Emergencies and Disasters, vol. 28, no. 2, pp.270-293.

IFRC 2016, Unseen, Unheard Gender-biased Violence in Disasters: Asia Pacific case Studies, Kuala Lumpur, Malaysia. At: www.ifrc. org/Global/Publications/Gender and Diversity/GBV in disasters AP report LR.pdf.

Ingber HW 2011, New Zealand: Domestic violence surges after earthquake, GlobalPost, Boston, 17 February 2011.

Jayarathne SS 2014, Women's potential in dealing with natural disasters: A case study from Sri Lanka, Asian Journal of Women's Studies, vol. 20, no. 1, pp.125-136.

Juran L 2012, The gendered nature of disasters: Women survivors in post-Tsunami Tamil Nadu, Indian Journal of Gender Studies, vol. 19, no. 1, pp.1-29. doi:10.1177/097152151101900101

Nelson V, Meadows K, Cannon T, Morton J \& Martin A 2002, Uncertain predictions, invisible impacts, and the need to mainstream gender in climate change adaptations, Gender and Development, vol. 10, no. 2, pp.51-59. doi:10.1080/13552070215911

Parkinson D 2017, Investigating the increase in domestic violence post-disaster: An Australian Case Study, Journal of Interpersonal Violence. doi:10.1177/0886260517696876

Parkinson D \& Zara C 2011, 'The way he tells it...': Relationships after Black Saturday', Women's Health Goulburn North East, Wangaratta, Victoria. At: www.genderanddisaster.com.au/wpcontent/uploads/2015/06/Doc-005-The-Way-He-Tells-it1.pdf.

Pincha C 2008a, Indian ocean tsunami through the gender lens: Insights from Tamil Nadu, India, Mumbai. At: www.academia. edu/2392574/Indian_Ocean_Tsunami_through_the_gender_lens. 
Pincha C 2008b, Gender Sensitive Disaster Management- A Toolkit for Practitioners, Mumbai. At: www. preventionweb.net/ files/7792_GndersensitivedisastermanagementToolkit.pdf.

Pongponrat K \& Ishii K 2018, Social vulnerability of marginalized people in times of disaster: Case of Thai women in Japan Tsunami 2011, International Journal of Disaster Risk Reduction, vol. 27, pp.133-141. doi:10.1016/j.ijdrr.2017.09.047

Reyes DD \& Lu JL 2016, Gender dimension in disaster situations: A case Study of flood prone women in Malabon City, Metro Manila, International Journal of Disaster Risk Reduction, vol. 15, pp.162-168. doi:10.1016/j.ijdrr.2015.11.001

Reynolds B \& Tyler M 2018, Applying a gendered lens to the stay and defend or leave early approach to bushfire safety, Australian Journal of Public Administration, vol. 77, no. 4, pp.529-541. doi:10.1111/1467-8500.12268

Rezaeian M 2013, The association between natural disasters and violence: A systematic review of the literature and a call for more epidemiological studies, Journal of Research in Medical Sciences: the official journal of Isfahan University of Medical Sciences, vol. 18, no. 12, p.1103. At: www.ncbi.n/m.nih.gov/pmc/articles/ PMC3908534/.

Russel-Smith J 2017, Savanna fire management and bushfire and natural hazard scenario planning for Northern Australia: annual project report 2016-17, Melbourne. At: www.bnhcrc.com.au/sites/ default/files/managed/downloads/na04_russell-smith_with_eu_ annualreport_2016-17_-_mpr_approved.pdf.

Saito F 2012, Women and the 2011 East Japan disaster, Gender and Development, vol. 20, no. 2, pp.265-279.

doi:10.1080/13552074.2012.687225

Sohrabizadeh S 2016, The neglect of women's capacities in disaster management systems in Iran: A qualitative study, Indian Journal of Gender Studies, vol. 23, no. 3, pp.467-480. doi:10.1177/0971521516656080

Statistical Centre of Iran 2013, Iran Statistical Yearbook 1392, Tehran, Iran. At: https://irandataportal.syr.edu/wp-content/ uploads/preliminary.pdf.

Takasaki Y 2012, Natural disasters, gender and handicrafts, Journal of Development Studies, vol. 48, no. 1, pp.115-132. doi:10.1080/00220388.2011.598509

Thapa SB \& Acharya G 2017, Women's health is not in focus in disaster zones: Lessons from the Nepal earthquake, Journal of Family Planning and Reproductive Health Care, vol. 43, no. 2, pp.92-93. doi:10.1136/jfprhc-2016-101605

Thornton W \& Voigt L 2007, Disaster rape: Vulnerability of women to sexual assaults during hurricane Katrina, Journal of Public Management and Social Policy, vol. 13, pp.23-49. At: http:// sites.google.com/a/jpmsp.com/www/Vol13/ss2-DisasterRapeThorntonandVo.pdf.
United Nations Development Programme (UNDP) 2015, Sustainable Development Goals. At: www.undp.org/sustainabledevelopment-goals.

United Nations Office of Disaster Risk Reduction (UNDRR) 2017, Disaster-related data for sustainable development Sendai Framework data readiness review 2017. Global summary report. At: www.undrr.org/publication/sendai-framework-data-readinessreview-2017-global-summary-report.

Valerio KA 2014, Storm of violence, surge of struggle: Women in the aftermath of Typhoon Haiyan (Yolanda), Asian Journal of Women's Studies, vol. 20, no. 1, pp.148-163. doi:10.1080/12259276.2014.11666177

WHO 2010, Gender, Climate Change and Health. At: www.ncbi. nlm.nih.gov/pubmed/25137107.

WHO 2017, Violence Against Women. At: www.who.int/news-room/ fact-sheets/detail/violence-against-women.

\section{About the authors}

Dr Tazrina Chowdhury is a research consultant at the Institute for Sustainable Futures, University of Technology Sydney. Her research focuses on women's experiences in the cyclone shelters of Bangladesh and strengthening community resilience in coastal communities.

Professor Paul Arbon AM is a Matthew Flinders Distinguished Professor and Director of the Torrens Resilience Initiative and the World Health Organization Collaborating Centre for Mass Gatherings and Global Health Security at Flinders University.

Dr Mayumi Kako is a graduate from Kobe City College of Nursing in Japan. She has completed postgraduate study at Flinders University. She ran a program to improve women's participation in disaster risk reduction in Japan.

Dr Robert Muller is a researcher and Adjunct Fellow at the Torrens Resilience Initiative. His research work is in globalisation, consumerism, resilience and mental health and the resilience of the deterrence effect. Robert's current research interest is in information disorder.

Dr Malinda Steenkamp is Principal Policy Officer in the Security and Emergency Management Team, Department of Premier and Cabinet, South Australia. She has worked at the Torrens Resilience Initiative at Flinders University.

Professor Kristine Gebbie is in the Faculty of Health Sciences, Flinders University and is a Fellow of the Torrens Resilience Initiative. Her major interests are in disaster preparedness and response. 